The International Journal Of Engineering And Science (IJES)

|| Volume || 6 || Issue || 1 || Pages || PP 66-70|| 2017 ||

ISSN (e): $2319-1813 \operatorname{ISSN}(\mathrm{p}): 2319-1805$

THE IJES

\title{
Advance Current Monitoring Techniques to Detect and Diagnosis the Inter-Turn Stator Fault in Three Phase Induction Motor
}

\author{
Fadhil Mohammad khalaf \\ Middle university / Electrical engineering technical college
}

\begin{abstract}
-
This paper presents the results of stator inter-turn fault detection and diagnosis in three phase induction motor using different types of current monitoring techniques such as: motor current signature analysis (MCSA), Current Concordia Vector, extend park vector approach (EPVA). Where the use of several signal processing techniques for extracting more information about the fault, will help us knowing the characteristics of each method in order to choose the best way to diagnose this type of machine fault. The tests show that the EPVA technique can diagnose the inter-turn fault with high accuracy compared with the other techniques. Because there is a similarity between the inter-turn frequency component and other machine faults frequency components (mixed air gap eccentricity, unbalance supply voltage) resulting a wrong discussion about the machine condition.
\end{abstract}

Keywords: induction motor, inter-turn, MCSA, Park vector, EPVA.

Date of Submission: 09 January 2017

$\longrightarrow$ Date of Accepted: 26 January 2017

\section{INTRODUCTION}

Nowadays three phase Induction motors are used in a wide variety industrial applications. They are the most used kind of electrical machines, because of their low manufacturing and maintenances cost, robust, high reliability, and hardness construction, as well as simplest speed control, especially after the great advances in power electronics field and drives.

In spite of the induction motor characteristics, the operation conditions and nature of mechanical loads make the machine exposed to several types of initial defects. These defects well developed over time causing reduce the machine efficiency and perhaps if these conditions persist may lead to catastrophic damage in the machine and out of work, causing great losses in production lines as well as additional maintenance cost.

To determine the changes that occur during the operation period, on - line condition monitoring is applied which helps to detect the faults at early stage and to identify their type, this provides the time it takes for diagnosis, maintenance, and reduce losses in production and the preservation of workers live[1]. Stator inter-turn fault in electrical machine is one of the popular fault, it represent about $30-40 \%$ of the total machine faults [2]. This fault is associated with insulation features that used to insulate the turns in induction motor coils. Where the accumulated number of factors lead to insulation breakdown [3], as shown in figure 1. Which causes dielectric treeing in insulation service and lead to partial discharge between turn to nearby turn, and if not treated (decrease the factor), this will evolve into disrepair damage to the neighboring coils, leading to phase failure, or developed to earth fault.

\section{SIGNAL PROCCESSING TACHANIQUES}

Nowadays stator current monitoring is one of the most widely technique used in fault diagnosis, because of high reliable, easy installation, simplicity. The current signal contains frequency components which can be related to a variety of faults such as mechanical and magnetic asymmetry, and shorted turns in the stator windings, etc. The current signal entered to PC unit usually using Hall effect current probes, then the information of the signal is extracted using some of signal processing technique, as:-

\subsection{Motor Current Signature Analysis (MCSA):-}

MCSA is a non invasive technique which diagnosis problems in induction motor by analyzing the current signal in time domain, or in frequency domain, or in time-frequency domain. It needs only

one phase current signal to obtain machine condition and no need to any other sensors (other phases) [4]. When a failure is present, the frequency spectrum of the line current becomes different from that of a non- faulted one. Such fault modulates the air gap and produces rotating frequency harmonics in the self and mutual inductances of the machine. Since the flux linkages oscillate at only the electric supply frequency, these harmonic 
inductances result in stator current harmonic at rotating frequency sidebands of the line frequency [5]. The characteristic of inter-turn frequency has been described in eq. (1) [2].

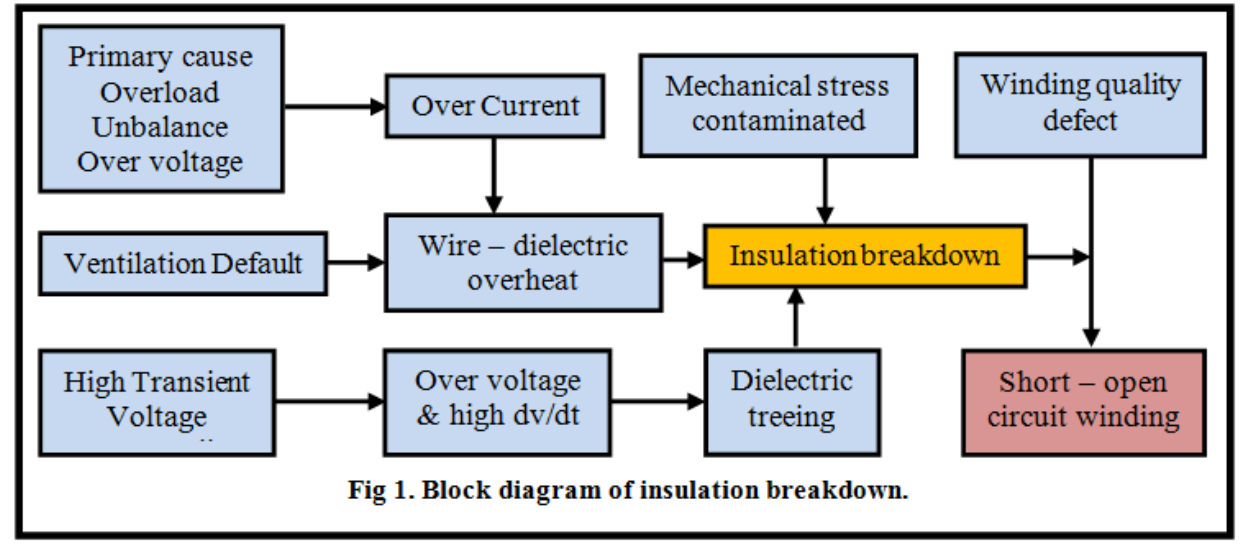

$$
\mathrm{F}_{\text {Inter-turn }}=\mathbf{f} \times\left(\frac{\mathrm{n}}{\mathrm{p}}(\mathbf{1}-\mathrm{S}) \pm \mathbf{k}\right)
$$

Where (f) is the fundamental supply frequency, (S) slip factor of the motor, (P) is number of pair of poles, $\mathrm{K}=1$, $2,3, \ldots \& \mathrm{n}=1,3, \ldots,(2 \mathrm{p}-1)$.

\subsection{Current Concordia Vector (CCV):-}

A two-dimensional (2-D) representation can be used to describe three-phase induction motor performance. A suitable 2-D representation is based on the current Concordia vector, sometimes by error called park vector. The current Concordia vector components $\left(i_{d}, i_{q}\right)$ are a function of main stator current $\left(i_{a_{a}} i_{b}, i_{c}\right)$ as [6]:

$i_{d}=\sqrt{\frac{2}{3}} i_{\alpha}-\frac{1}{\sqrt{6}} i_{b}-\frac{1}{\sqrt{6}} i_{c}$

$i_{\mathrm{q}}=\frac{1}{\sqrt{2}} i_{\mathrm{b}}-\frac{1}{\sqrt{2}} i_{\mathrm{c}}$

when a motor without faults, works through a three-phase system of sinusoidal currents, balanced and of positive sequence, the components of the Park vector form are a circle centered in the origin of the plane D-Q with a constant radius. In case of a short circuit in stators winding or any unbalance percentage in supply voltage, the motor behaves as an unbalanced load and such unbalances cause an oscillation in the radius of the Park vector and turn into elliptical shapes.

\subsection{Extend Park Vector Approach (EPVA):-}

The Extended Park's Vector Approach (EPVA) is based on the spectral analysis of the AC level of the current Park's Vector modulus, which given in eq. (4) [7].

$i_{\mathrm{w}}=\sqrt{i_{d}{ }^{2}+i_{q}{ }^{2}}$

under healthy conditions, the EPVA signature will be clear from any frequency component, i.e., only a DC offset value is present in the current Park's Vector modulus [6]. The occurrence of winding inter-turn short circuits leads to asymmetry in the motor, and creation negative sequence components in the current signal.

Now the EPVA signature shows an increment in the magnitude of the spectral component at twice of the fundamental supply frequency (2f), as compared to a healthy condition. The (2f) component is directly related to the asymmetries in the stator turns. The amplitude of this spectral component is directly related to the extension of the fault [7].

\section{LABROTORY TESTS}

A detection and diagnosis system has been built, which consists of three Hall effect current sensors type LA 25NP (LEM company). These probes was used to test three phase induction motor with the following characteristics (380 V, $1.1 \mathrm{KW}, 4$ Pole, $1410 \mathrm{rpm})$. The current signals was interred to PC using PCI 1710 data acquisition card (Advantech company). Mat lab program has been used to built the analysis software required for the analysis the signals using Fast Fourier Transform (FFT), park Vector, and EPVA. The current signal have been the entered to PC using the sampling frequency equal $\left(\mathrm{F}_{\mathrm{s}}=4096 \mathrm{~Hz}\right)$ and number of samples $\left(\mathrm{N}_{\mathrm{s}}=\right.$ 32768). Figure 2 shows stator current monitoring system. The three phase stator winding was modified to have a variable inter-turn short circuit fault $(3,5,9,27$ shorted turn). 


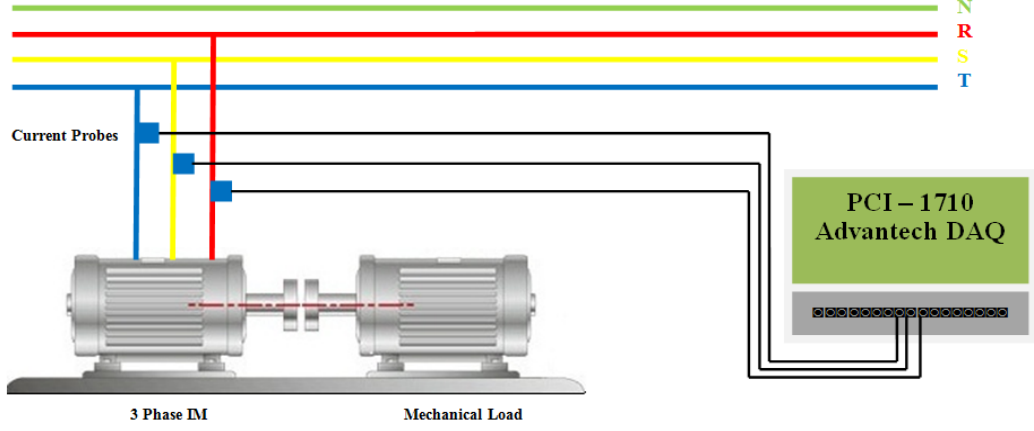

Fig 2. Detection and diagnosis sy

The results was obtained from the different operating situations, as follows:

\subsection{Fault Detection Using MCSA Technique:-}

If there is inter turn fault in the stator coil the current spectrum will content fault frequency component which obtain by the sidebands component near $(26 \mathrm{~Hz}, 74 \mathrm{~Hz})$, as established eq. (1). For our motor (50 Hz supply frequency, 1410 r.p.m full load speed, 0.06 slip). By obtained figure 3-a. We see that at normal condition (Healthy induction motor) the sideband component has not been appeared at estimated locations, and there is ($35 \mathrm{~dB}$ ) DC offset value in the current spectrum. Sometimes there is small magnitude of sideband component will appear at the estimated frequency, this is because of there is an acceptable percentage of mixed air gap eccentricity fault cause this component. But by increasing the fault severity (number of shorted turns) the fault frequency components will appear. We see that the lift side band component $(25.75 \mathrm{~Hz})$ will increase significantly $(-40 \mathrm{~dB})$ compared with the right sideband component $(72.25 \mathrm{~Hz})$. as shown in figure 3-b. Also we see that the DC offset component increased to $(-29.16 \mathrm{~dB})$.

\subsection{Fault Detection Using Current Concordia Technique:-}

In order to increase the accuracy of diagnosis the inter-turn fault in three phase induction motor, Current Concordia technique has been used. Figure 4-a shows the park vector form in case of healthy induction motor, balance supply voltage, which assume as uniform circle without any bended. But by observing figure 4-b we see that there is a small elliptic shape begun to appear at $1 \%$ unbalance supply voltage. This small percentage will confuse the monitoring person about there is some inter-turn fault at its early stage. Figure 4-c shows the park vector form in case of 13 shorted turns (in one phase) are existed in induction motor stator winding. But if there is number of inter-turns fault at each phase the park vector will be deferent, and figure 4-d make its clear.

Figure 4-e shows how the park vector form will be at severe damage in specified coil or at occurring phase failure at one of the three phase.
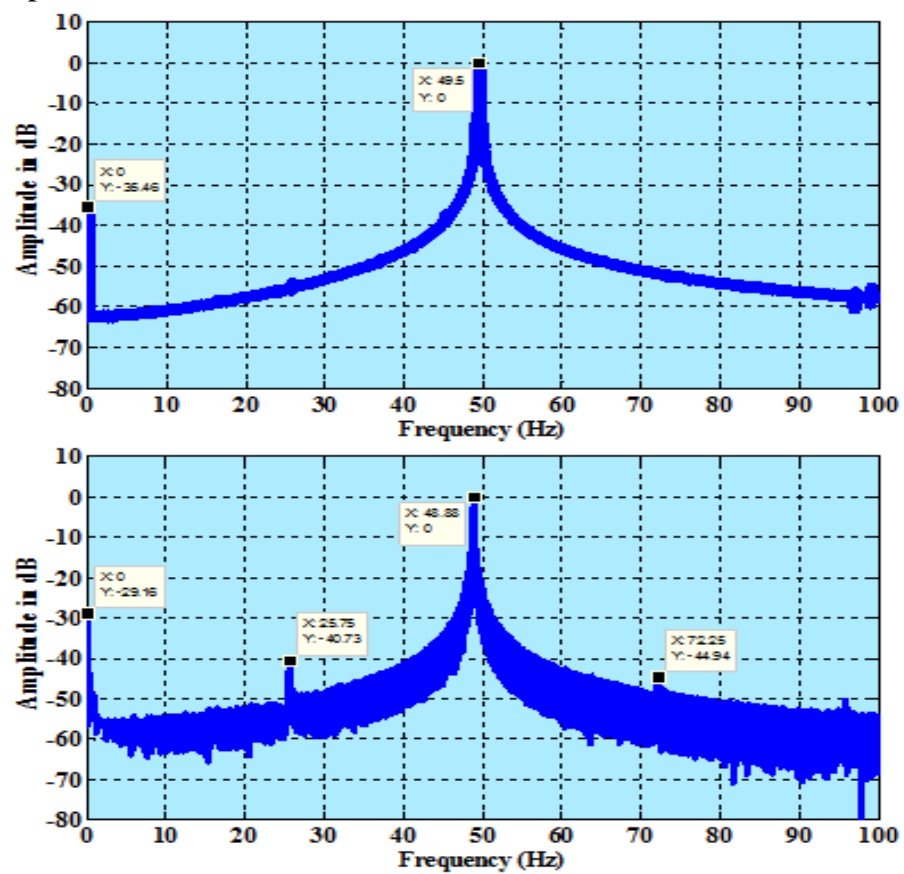

Fig.3: current spectrum in case of: (A) Normal Condition. (B) 27 shorted turn 

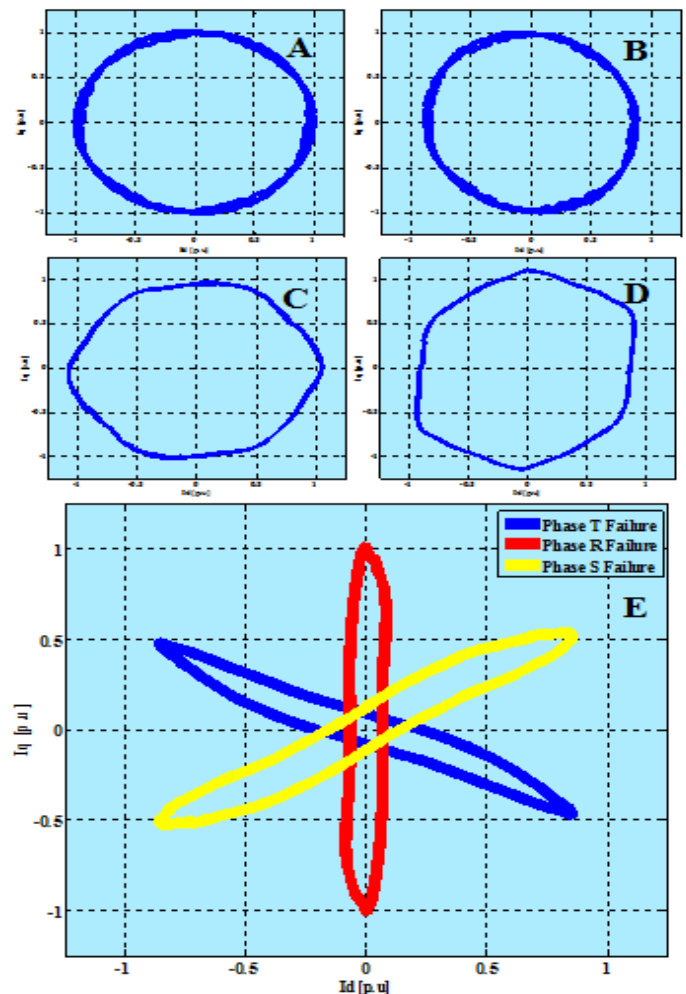

Fig 4: Park Vector Form In Case Of :

(A) Normal Condition.

(B) $1 \%$ Unbalance Supply.

(C) 13 Shorted Turn.

(D) $(3,9,13)$ Shorted Turn At Different Phases.

(D) Severe Damage At Different Phases.

We see that the Park vector technology has some of disadvantages, the ratio for any imbalance in the supply currents causes the appearance of elliptic shape as mentioned before, and also the small percentage of bending in the elliptic shape will not obtain the existence of the inter turn fault at early stage.

\subsection{Fault Detection Using EPVA:-}

EPVA helps to detect inter turn fault more easily and accurately by monitoring the twice supply frequency (2f) component which appear in frequency spectrum of park currents amplitude. Figure (5-a) shows the park currents waveform in time domain ( Id in red, Iq in blue, and the AC component magnitude in dash-green). Also figure (5-b) show that we can detect the inter-turn fault at very early stage by observing appearing the $2 \mathrm{f}$ component and we can give correct discussion about machine condition without any adopt of existing any other fault. As the magnitude of $2 \mathrm{f}$ component is directly proportional to the number of shorted turn so we can detect the approximately number of shorted turns in machine coil.

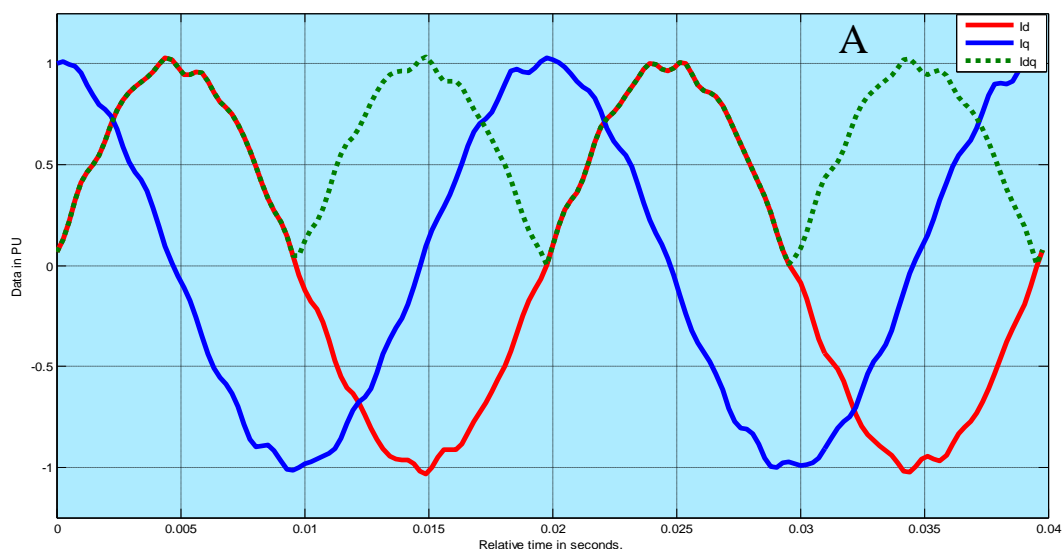




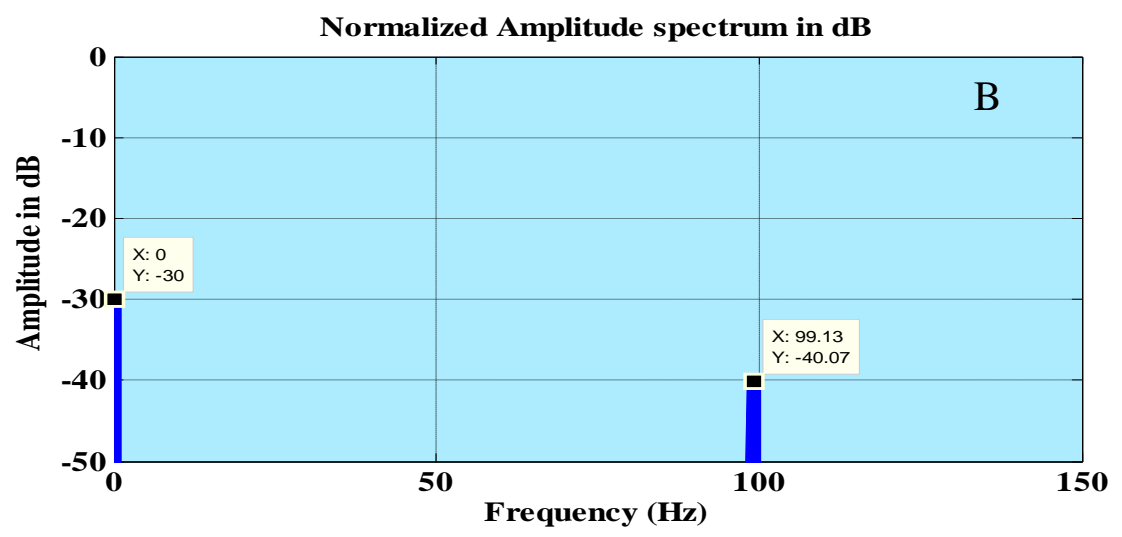

Fig 5: Basic of EPVA operation:

(A) Direct component $\mathrm{I}_{\mathrm{d}}$, Quadrant component $\mathrm{I}_{\mathrm{q}}, \mathrm{I}_{\mathrm{dq}}$.

(B) 27 shorted turn.

\section{CONCLUSIONS}

Paper presents the application of current monitoring techniques (MCSA, Current Concordia, and EPVA) for diagnosing the occurrence of inter-turn short-circuits in the windings of operating three-phase induction motor. The proposed of using all these techniques is to chose the best technique for detection the inter-turn fault: MCSA is a powerful technique for monitoring and diagnosis the machine condition. The measurement of one stator current helps to detect most of electrical machine faults. MCSA can detect the inter turn by monitoring the fault frequency sidebands, especially the left sideband component. The limits of this technique is that even at healthy machine condition the sideband components will appear because of there is an allowable percentage of mixed air gap eccentricity cause to create side band component equal to ( $\left.\pm F_{s h}\right)$, ( $F_{s h}$ is machine rotational frequency).

Current Concordia technique has the ability to detect stator inter-turn fault, and if its detect, we can locate the fault at which phase, by recognizing the elliptic form bend direction on the D-Q axis. In spite of the Current Concordia characteristics, it has some disadvantages like: it's difficult to detect the fault at early stages. Because of the difficulty of observing the elliptic form bend and the elliptic form will appear in case of unbalance supply voltage.

The tests shows that the EPVA technique can diagnose the inter-turn fault with high accuracy compared with the other techniques, by monitoring the (2f) component in the park current spectrum. The (2f) component will appear if there is inter-turn fault in any phase.

So my suggestion is to use EPVA and current Concordia together to give the right discussion about the fault existing and its location.

\section{REFERENCES}

[1]. P. J. Tavner, "Review of Condition Monitoring of rotating Electrical machines", IET Electric Power application, Vol. 2, No. 4, pp. 215-247, 2008

[2]. C. j. Verucchi, G. G. Acosta, and F. A. Benger, "A Review on Fault Diagnosis of Induction Machines", Latin American Applied Research (38), PP. (113-121), 2008.

[3]. MahfoudChafai, and LarbiRefoufi, "Large Squirrel Cage Induction Motor Reliability Modeling", Journal of Engineering and Applied Sciences 2 (5), PP. (909-914),2007.

[4]. G. B. Kliman and j. Stein, "Methods of Motor Current Signature Analysis", Electrical Machines and Power systems, Vol. 20, No. 5, PP. (463-474), 1992.

[5]. A. Stavrou, H. Sedding, and J. Penman, "Current monitoring for detectinginter-turn short circuits in induction motors," in Proc. IEEE Int.Electric Machines and Drives Conf., Seattle, WA, May 9-12,PP. (345-347), 1999.

[6]. Sergio M. A. Cruz, A. J. Marques Cardoso, "Stator Winding Fault Diagnosis in Three-Phase Synchronous and Asynchronous Motors, by The Extended Park's Vector Approch", IEEE Transactions on Industry Applications, Vol. 37, No. 5, 2001.

[7]. L. M. R. Oliveira and A. J. Marques Cardoso, "Incipient turn-to-turn Winding Fault Diagnosis of Power Transformers by The onload Exciting Current Extended Park's Vector Approach", Advanced Research Workshop on Moderen Transformers. 28-30 October 2004, Vigo - Spain 